\title{
Early correction of a developing Class III Malocclusion with a removable appliance
}

\author{
André Wilson Machado ${ }^{*}$, Sergei G Rabelo Caldas ${ }^{2}$ and Luiz Guilherme Martins Maia ${ }^{3}$ \\ ${ }^{1}$ Federal University of Bahia, School of Dentistry, Brazil \\ ${ }^{2}$ Federal University of Rio Grande do Norte, School of Dentistry \\ ${ }^{3}$ Department of Orthodontics, School of Dentistry, Tiradentes University
}

\begin{abstract}
Class III malocclusion remains one of the most difficult to treat and its treatment timing has always been controversial. The purpose of this report was to present the case of a 6-year-old patient with a Developing Class III malocclusion and anterior crossbite treated early using a simple and effective maxillary removable appliance. The proposed intervention involved the construction of a removable appliance with digital springs. A 4.5 years follow-up evaluation showed favorable results demonstrating the efficacy of the approach undertaken as well as its stability. This case demonstrates that in specific cases such as this report, when this problem is identified and treated early, pediatric dentists have the opportunity to minimize the complexity of future orthodontic treatment and limit the extent of malocclusion in the permanent dentition.
\end{abstract}

\section{Introduction}

Although class III malocclusion is very well studied in the literature it remains one of the most difficult to treat. Different aspects of this malocclusion such as its diagnosis and different treatment modalities are very well documented. On the other hand, timing of treatment, especially for children with developing Class III malocclusions in the early mixed dentition, has always been controversial and hence the decision whether to treat early or to wait until the end of growth is difficult [1,2].

This issue becomes a dilemma when dealing with skeletal class III patients. Conversely, there is a consensus that pseudo class III malocclusion requires an early intervention since it has no selfcorrection. A common characteristic found in the pseudo class III malocclusion is the anterior crossbite. This problem should be corrected at the earliest time possible because the anterior interlock could interfere in the maxillary growth and dental development, which can aggravate the class III disharmony [3-5]. In such cases the treatment is aimed to help establish a favorable environment for the growth of the maxilla $[1,6]$.

The aim of this case report is to present a simple method to early correct a developing class III malocclusion in a 6-year-old patient highlighting the importance of early diagnosis and intervention.

\section{Description of the case}

A Brazilian boy, aged 6 years and 2 months, was referred to the orthodontist because his parents were worried about his prominent lower anterior teeth and facial appearance. His medical and dental histories were uneventful and oral hygiene and gingival conditions were within normal standards. There was no familial tendency of true class III malocclusion.

Facial evaluation showed a concave profile and the frontal view revealed a favorable facial symmetry. Intraoral examination revealed an early mixed dentition stage, with erupted lower permanent central incisors and first molars. He presented with an anterior crossbite (overjet $-3.0 \mathrm{~mm}$ ) and deep bite (overbite $+3.5 \mathrm{~mm}$ ). The second primary molars showed a mesial step relationship and the canines a mild class III relationship on both sides (Figure 1). On assessment of the CR-HO (centric relation - habitual occlusion) discrepancy and guidance of the mandible on closure, no functional shift was seen.

Our treatment objectives were (1) to correct anterior crossbite and (2) provide a normal environment for the growth of the maxilla.

Treatment was started with a removable maxillary appliance with three specific characteristics, (1) springs were placed on the lingual side of the upper maxillary anterior primary teeth to induce labial movement, (2) an anterior bow fabricated with $0.8 \mathrm{~mm}$ stainless steel was placed on the labial side of the lower incisors to act as a retainer as

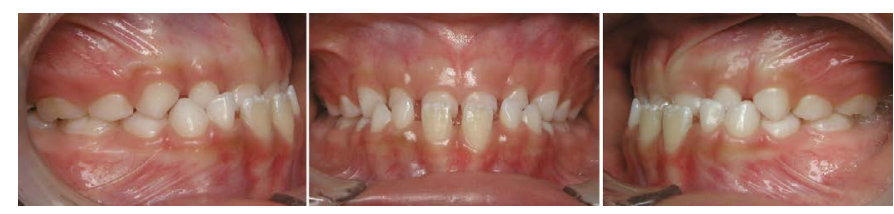

Figure 1. Pretreatment intraoral photographs.

Correspondence to: Andre Wilson Machado, DDS, MS, PhD, Av. Araújo Pinho, 62, $7^{\circ}$ andar, Faculdade de Odontologia da Universidade Federal da Bahia, Salvador/BA, Brazil. Cep: 40.110-150, Tel: 55 (71) 3336-6973; E-mail: andre@andrewmachado.com.br

Key words: class III malocclusion, interceptive orthodontics, early treatment, anterior cross bite

Received: September 19, 2016; Accepted: October 03, 2016; Published: October 07,2016 
well as to provide lingual forces and (3) a posterior acrylic biteplane was included to reduce anterior overbite allowing proper labial movement of the upper primary incisors (Figure 2). The patient was instructed to wear the appliance for as long as possible and also to remove it during mealtimes. For three months only the upper springs were activated and when favorable positioning of the upper primary incisors was achieved, posterior biteplane was removed and thereafter, anterior lower bow was activated.

After six months of treatment, patient presented with a normal anterior relationship whereas posterior occlusion remained unchanged (Figure 3). At this phase, a new appliance was fabricated as a retainer until the eruption of the upper anterior permanent central incisors, which took 1 year and one month (Figure 4). After proper anterior overjet establishment treatment was discontinued and the patient was kept under observation in a six-month basis evaluation (Figure 5).

A 4 years' follow-up evaluation showed a favorable overjet and overbite and an improved facial profile demonstrating the efficacy of the treatment undertaken as well as its stability (Figure 6). Due to the relapse Class III malocclusion tendency the patient will be kept under observation till the end of pubertal growth spurt.
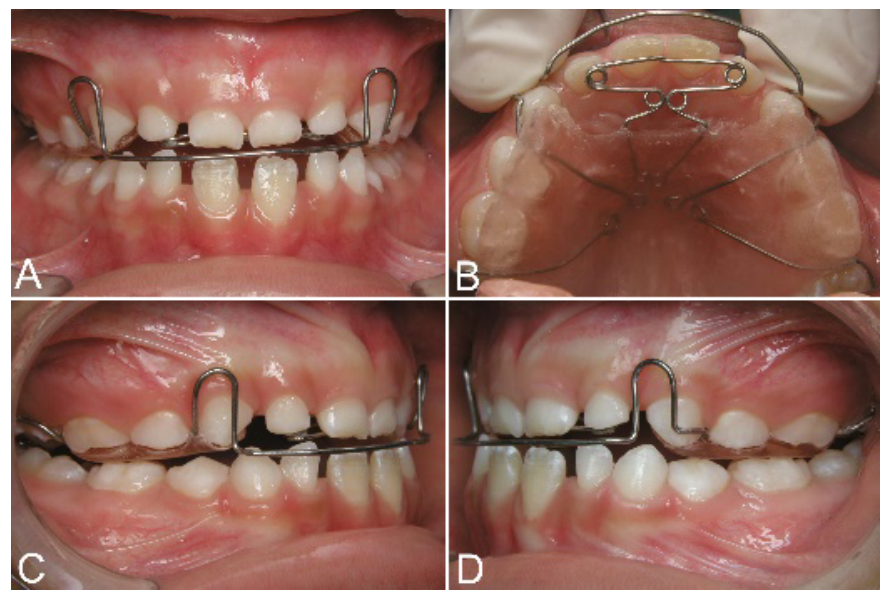

Figure 2. Removable Appliance used: A - frontal view; B - oclusal view showing the springs; $\mathrm{C}$ and $\mathrm{D}$ - lateral views.

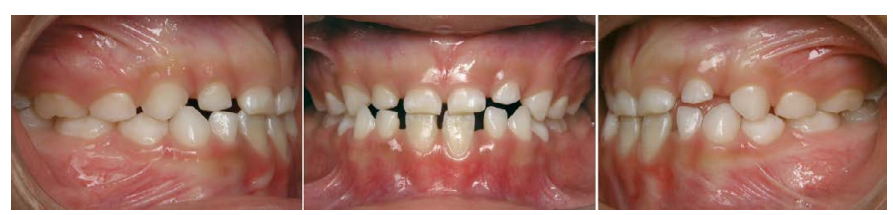

Figure 3. Results after three months of treatment.

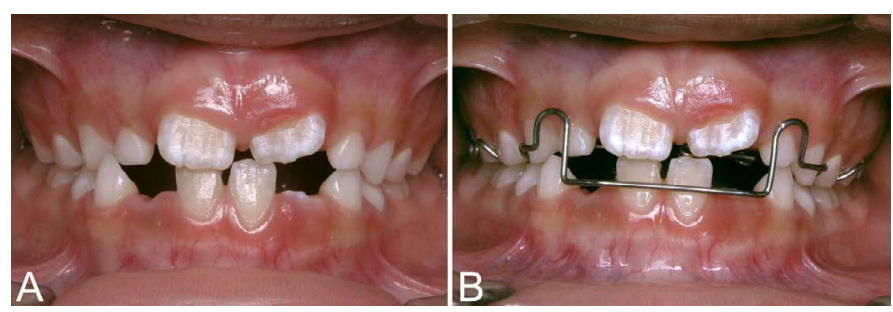

Figure 4. A - Results after one year and one month of treatment and B - New Appliance used as a retainer.

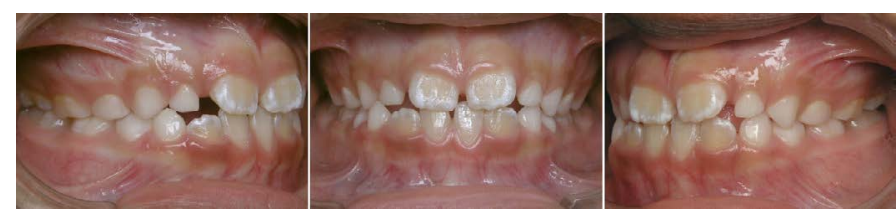

Figure 5. Results presented when treatment was discontinued.
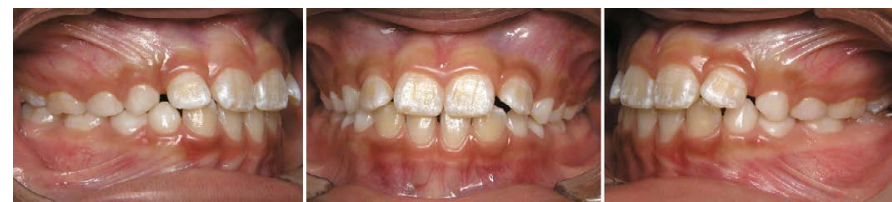

Figure 6. Follow-up intraoral photographs after 4 years.

\section{Discussion}

The optimal time to intervene in a developing Class III malocclusion seems to have a fundamental role in predicting good results $[1,2]$. On regard of this issue a controversial question arises: when is the best time to start a Class III malocclusion treatment? [1]. One of the most important reason one should intercept a developing Class III malocclusion at the earliest time possible is that this problem shows a significant tendency to worse with time $[5,7,8]$. According to the literature this unfavorable growth tendency seems to be related to a long period of active mandibular growth, the absence of any catch-up growth in the maxilla, and the significantly more vertical direction of facial growth [8].

Although the ideal timing for skeletal Class III remains controversial in the literature, pseudo Class III must be intercepted at the earliest time possible $[2-4,7,9]$. Since pseudo Class III is characterized by dental problems, the early treatment is aimed at correcting the angulation of the upper incisors and hence eliminating the mechanical interference caused by the overclosure of the mandible due to the anterior cross bite maximizing the growth potential of the naso-maxillary complex $[1,4]$. The other major reason for this early anterior crossbite correction is to avoid some complications often associated with it such as, lower incisors gingival recession, excessive incisal wear, increased chances of temporomandibular joint (TMJ) dysfunction, a compromised dental and facial esthetics and associated negative psychosocial effects [9].

According to the literature the optimal time to intervene in a Class III malocclusion seems to be when the maxillary permanent incisors erupt [10]. In the case presented treatment was initiated at a 6-yearold age, some months before this ideal stage. The reason for this early intervention was to correct the primary incisors angulation in order to create a favorable environment for permanent incisors eruption. Literature supports this early intervention, which renders more favorable results [11] and a definitive reduction in treatment time [12]. A long-term study comparing patients treated in the primary and early mixed dentition with patients treated in the late mixed dentition showed that, at the end of phase 2 therapy, greater forward movement of the maxilla and less mandibular projection were found only in the early treatment group [11].

In order to intercept this malocclusion different appliances have been used, such as maxillary expansion, removable plates with springs, fixed or removable inclined planes, functional appliances, chin-cups, and simple fixed appliances associated or not to dental extraction [2$4,5,13,14]$. In the case presented, an upper removable appliance with springs and an anterior lower bow was used. This appliance has already 
been used in the literature with good clinical results and as called by different names such as Progenic Modified Appliance [15] and Eschler Arch [16]. After evaluating the results obtained and the follow-up photos it can be stated that this approach provided good results and stability. The use of maxillay removable appliance is an efficient method to procline upper incisors in postural Class III malocclusion and can also improves soft tissue profile [14]. It is necessary to remember that in order to achieve those results patient compliance is of fundamental importance.

Another problem encountered in Class III patients is the long-term stability. Although literature shows encouraging results with facemask therapy, great relapse tendencies are also found which points out that a consistent retention phase is needed as well as longer periods of followup $[5,9,17]$. In the case presented a removable appliance was used as retention until upper incisors proper eruption thereafter treatment was discontinued. According to the literature a positive overjet and overbite at the end of treatment appears to maintain the anterior occlusion [1]. On the other hand, since Class III patients grow similar to untreated Class III patients after treatment, the patients need to be kept under observation till the time they pass the third growth spurt at 18 years of age $[5,17]$.

- In summary, although treatment ideal timing of Class III malocclusions is a controversial issue all efforts should be made towards an early correction of a developing class III malocclusion, especially when associated to anterior cross-bite.

\section{References}

1. Ngan P (2006) Early treatment of Class III malocclusion: is it worth the burden? Am J Orthod Dentofacial Orthop 129: S82-85. [Crossref]

2. Araújo EA, Araújo CV (2008) Abordagem clínica não-cirúrgica no tratamento da má oclusão de Classe III. Dent Press J Orthod 13: 128-157.

3. Gu Y, Rabie AB, Hägg U (2000) Treatment effects of simple fixed appliance and reverse headgear in correction of anterior crossbites. Am J Orthod Dentofacial Orthop 117: 691-699. [Crossref]
4. Hägg U, Tse A, Bendeus M, Rabie AB (2004) A follow-up study of early treatment of pseudo Class III malocclusion. Angle Orthod 74: 465-472. [Crossref]

5. Kapur A, Chawla HS, Utreja A, Goyal A (2008) Early class III occlusal tendency in children and its selective management. J Indian Soc Pedod Prev Dent 26: 107-113. [Crossref]

6. Kanno Z, Kim Y, Soma K (2007) Early correction of a developing skeletal Class III malocclusion. Angle Orthod 77: 549-556. [Crossref]

7. Kanas RJ, Carapezza L, Kanas SJ (2008) Treatment classification of Class III malocclusion. J Clin Pediatr Dent 33: 175-185. [Crossref]

8. Baccetti T, Franchi 1, McNamara JA (2007) Growth in the untreated Class III subject Semin Orthod 13: 130-142.

9. Turley PK (2007) Treatment of the Class III Malocclusion with Maxillary Expansion and Protraction. Semin Orthod 13: 143-157.

10. Proffit WR (2000) Contemporary Orthodontics. (3rd edn.) Philadelphia: Mosby; 511513.

11. Franchi L, Baccetti T, McNamara JA Jr (2004) Postpubertal assessment of treatment timing for maxillary expansion and protraction therapy followed by fixed appliances. Am J Orthod Dentofacial Orthop 126: 555-568. [Crossref]

12. Saadia M, Torres E (2000) Sagittal changes after maxillary protraction with expansion in class III patients in the primary, mixed, and late mixed dentitions: a longitudinal retrospective study. Am J Orthod Dentofacial Orthop 117: 669-680. [Crossref]

13. Cozza P, Marino A, Mucedero M (2004) An orthopaedic approach to the treatment of Class III malocclusions in the early mixed dentition. Eur J Orthod 26: 191-199. [Crossref]

14. Alhaija ESJA (2006) Skeletal, Dental and Soft Tissue Changes in Postural Class III Malocclusion Treated with a Maxillary Removable Appliance. J Clin Pediatr Dent 31: 149-152.

15. Palma PC, Figueiredo JFB, Gandini LG, Gandini MREAS (2004) Aparelho progênico modificado: suas partes constituintes e aplicações clínicas. J Bras Ortodon Ortop Facial 54: 561-568.

16. Gonçalves FA, Nouer DF, Magnani MBBA, Kuramae M, Inoue RC (2003) O Aparelho progênico como opção de tratamento da má oclusão de Classe III - relato de caso clínico. Rev Assoc Paulista de Espec Ortodon 3: 57-63.

17. Tortop T, Keykubat A, Yuksel S (2007) Facemask therapy with and without expansion. Am J Orthod Dentofacial Orthop 132: 467-474. [Crossref]

Copyright: (C2016 Machado AW. This is an open-access article distributed under the terms of the Creative Commons Attribution License, which permits unrestricted use, distribution, and reproduction in any medium, provided the original author and source are credited. 